\title{
Novel Regenerative Solutions Induce Rapid Adipogenic Differentiation of Mesenchymal Stem Cells with No Evidence of Transformation or Osteogenic Differentiation
}

\author{
Denis O. Rodgerson ${ }^{1}$, Alan Harris ${ }^{1}$, Vincent C Giampapa ${ }^{2}$, Steven J. Greco ${ }^{3}$, \\ David O'Neill ${ }^{1}$ and Pranela Rameshwar ${ }^{3}$ \\ ${ }^{1}$ NeoStem, New York, NY, USA \\ ${ }^{2}$ Dept. of Surgery, Division of Plastic Surgery, UMDNJ-New Jersey Medical School, Newark, NJ, USA \\ ${ }^{3}$ Dept. of Medicine-Hematology/Oncology, UMDNJ-New Jersey Medical School, Newark, NJ, USA
}

Correspondence should be addressed to: Denis O. Rodgerson; drodgerson@neostem.com

Received 17 January 2012; Accepted 5 February 2013; Published 24 April 2013

Academic Editor: Ludmilla B. Buravkova

Copyright @ 2013 Denis O. Rodgerson, Alan Harris, Vincent C Giampapa, Steven J. Greco, David O'Neill and Pranela Rameshwar. Distributed under Creative Commons CC-BY 3.0

\begin{abstract}
Adipose tissue is commonly used in plastic surgery procedures and is also a rich source of mesenchymal stem cells (MSCs). Since MSCs are functionally plastic cells, adipose tissue may provide a promising cell source for regenerative medicine applications. We have developed two mixed growth factor formulations (termed "dermal" and "fat" factor formulations) to be used with autologous adipose tissue to help induce the regeneration of human skin and subcutaneous tissue. In this study, we investigate the effect of these formulations on proliferation and differentiation of MSCs obtained from human bone marrow and from adipose tissues. Lower concentrations of both formulations had no effect on MSC proliferation, but induced rapid adipogenic differentiation. At higher concentrations, both formulations induced MSC death. There was no evidence of osteogenesis ormalignant transformation at any concentration, as judged by absence of foci formation, inability of the cells to be serially passaged and absence of colonies in methylcellulose matrix. Thus, at optimal doses these factor formulations promote rapid differentiation of MSCs into adipogenic cells, with no evidence of cell transformation or osteogenic induction. These studies have implications for wound healing and tissue regeneration, as well as cosmetic applications to enhance the deficits seen in aging skin and in facial volume loss.
\end{abstract}

Keywords: Mesenchymal stem cells, adipose tissue, growth factors, adipogenesis, skin regeneration.

\section{Introduction}

The use of adult and embryonic stem cells to repair, replace and protect tissues is an active area investigation (Yan et al (2005), Trzaska et al (2009), Kim et al (2009), Patel et al (2012) ). However, compared to embryonic stem cells (ESCs), adult stem cells such as

Cite this Article as: Denis O. Rodgerson, Alan Harris, Vincent C Giampapa, Steven J. Greco, David O'Neill and Pranela Rameshwar (2013), "Novel Regenerative SolutionsInduce Rapid Adipogenic Differentiation of Mesenchymal Stem Cells with no Evidence of Transformation or Osteogenic Differentiation," Advances in Stem Cells, Vol. 2013 (2013), Article ID 716906, DOI: 10.5171/2013. 716906 
mesenchymal stem cells (MSCs) have no ethical concerns associated with their use. Other potential advantages of MSCs are a lower probability of tumor formation compared to ESCs, and their ability to be transplanted across allogeneic barriers (Trzaska et al (2009), Mohseny et al (2009), Molcanyi et al (2009) ). The latter provides MSCs with a major advantage since these cells could be immediately available as an offthe-shelf source. MSCs have the ability to differentiate into bone, cartilage and fat cells; are capable of exerting both immune suppressive and enhancer functions(Greco et al (2007), Tao et al (2009),Greco et al (2008), Wang et al (2009), Buron et al (2009), LeBlanc et al (2008), Potian et al (2003), Romieu-Mourez et al (2007), Chan et al (2006), Stagg (2007), Tang et al (2008) ); and may also be able to differentiate into specialized cells, such asneurons and cardiomyocytes (Trzaska et al(2009), Greco et al @007) Cho et al (2005), Greco et al (2007), Cho et al (2009);).

MSCs are relatively ubiquitous in adults, where they are mostly present in bone marrow and adipose tissue (Campagnoli et al (2001), Castillo et al (2007), Dominici et al (2009) ). In bone marrow, MSCs are located around blood vessels and bone trabeculæ (Castillo et al (2007), Sakaguchi et al (2004)). MSCs can be obtained with ease through bone marrow aspiration or from discarded adipose tissues. There is evidence that MSCs have the potential for treating neurological and other disorders (Momin et al (2010), Totey et al (2009) ), although a few in vitro studies have raised questions about their safety. In particular, the repressor RE-1 silencing transcription factor (REST) expressed in MSCs has also been linked to oncogenesis (Greco et al (2007), Kreisler et al (2010), Majmader (2006) ). In addition, MSC transformation following long-term culture was reported (Rosland et al (2009). However, to date the systemic infusion of human adipose tissue-derived MSCs in both animals and humans has not been associated with tumor formation (Isakova et al (2007), Ra et al (2011) )0.

MSCs can be differentiated in vitro by various methods to generate specialized cells, such as neuronal cells and cardiomyocytes (Cho et al (2009)Greco et al (2007)). However, the in vivo differentiation of MSCs and the ability of MSCs to respond to the microenvironment after implantation remains an area of active investigation (Sherman et al (2011)). We have developed two novel growth factor formulations for use with autologous adipose tissue to induce the regeneration of human skin and soft tissue in vivo. Here, we describe in vitro studies to better understand the biology of these factors with regards to differentiation and transformation of MSCs. In these studies we observe rapid differentiation to adipocytes with no evidence of malignant transformation. The data indicates that these solutions of fat and dermal growth factors may promote endogenous reconstruction and regeneration of damaged or aged tissue by differentiating the patients' own stem cells along the adipocyte lineage.

\section{Materials and Methods}

\section{Reagents and Antibodies}

Dermal and fat factors were prepared under good manufacturing practice. Dermal factor solution contained $0.91 \mu \mathrm{g} / \mathrm{mL}$ estriol and $19.1 \mu \mathrm{g} / \mathrm{ml}$ of hyaluronic acid and fat factor solution, $0.0009 \mu \mathrm{g} / \mathrm{mL}$ sodium liothyronine, $0.341 \mu \mathrm{g} / \mathrm{ml}$ sodium levothyronine, 0.1818 $\mathrm{U} / \mathrm{mL}$ humulin $\mathrm{R}$ and $0.0019 \mu \mathrm{g}$ of hyaluronic acid. Ficoll-hypaque; tissue culture grade PBS; collagenase and DMEM with high glucose were purchased from Sigma (St Louis, MO). BiocoatMatrigel Matrix; FITCanti-human CD29; PE-anti-human CD29; FITC-anti-human CD45; PE-anti-human CD34 and APC-anti-human CD44 were purchased from BD Biosciences (Franklin Lakes, NJ). Vybrant CFDA-SE Cell Tracer from Invitrogen (Grand Island NY); CyQUANT Cell Proliferation Assay; Platinum SYBR Green qPCRSuperMix-UDG Kit; Super Script III reverse transcriptase; RNase A and Platinum Taq polymerase were purchased from Invitrogen (Carlsbad, CA). FITC-anti-human CD105 was purchased from Cymbus Biotechnology (Hants, UK), anti-human prolyl-4-hydroxylase (PH4) MAb from Bachem (Torrance, CA). 


\section{Study Subjects}

Human MSCs were expanded from bone marrow aspirates and from liposuction material of healthy donors, aged 20-35 yrs. Adipose-derived MSCs were cultured from discarded tissues of subjects undergoing elective liposuction. The bone marrow aspirates (for controls) were selected from donors, 20-35 yrs whereas the liposuction was obtained from donors, 40-58 yrs. The liposuction donors were four females and two males. The bone marrow donors were two males and one female. Adipose-derived MSCs were cultured from discarded tissues of subjects undergoing elective liposuction. The tissue was harvested under local anesthesia using buffered $0.5 \%$ lidocaine with epinephrine 1:200000 and the cells were extracted with manual suction ingusinga 10 cc syringe attached to 16 gauge mushroom needle. All procedures were approved by the Institutional Review Board of the University of Medicine and Dentistry of New JerseyNewark Campus.

\section{Culture of Human MSCs}

MSCs were cultured from bone marrow aspirates and from liposuction tissues, as previously described (Trzaska et al (2009), Potian et al (2003), Yoshimura, et al (2006)). Unfractionated bone marrow aspirates were cultured in DMEM with 10\% FCS (D10 media) in Falcon 3003 dishes. After 3 days, red blood cells and granulocytes were removed with
Ficoll-hypaque. The fatty tissues from liposuction were digested with $0.08 \%$ of collagenase. To reduce the time in collagenase, the tissues were first homogenized. The mixture was centrifuged at $500 \mathrm{~g}$ for $10 \mathrm{~min}$. The pellet was saved and then washed in PBS and the cells $\left(5 \times 10^{6}\right)$ were seeded as for bone marrow mononuclear cells. At $80 \%$ confluence the cells were trypsinized and then passaged up to four times. The adherent cells were morphologically symmetric. Phenotypic characterization by flow cytometry indicated CD14-, CD29+, CD44+,CD34-, CD45-, CD105+, prolyl-4-hydroxylase-, PH4 (13).

\section{Stimulation of MSCs/Optimization of Factors}

The range of factors used in the in vitro studies reflect the concentrations used in clinical procedures conducted by Dr. Vincent Giampapa. Table 1 shows the concentrations of the components within each solution of fat and dermal factor. These concentrations were based on standard procedures to transplant fat tissues from patients. Based on the clinical experience, combined with the literature on aging, skin laxity and volume loss, we developed the novel components for each factor to enhance the efficacy of autologous adipose tissues. The premise is that the listed factors would replace the deficiency to facilitate cell replacement of the transplanted adipose cells, which comprise MSCs.

Table1. Components of Fat and Dermal Factors

\begin{tabular}{|l|l|l|}
\hline Components & $\begin{array}{l}\text { Fat } \\
\text { Factor }\end{array}$ & $\begin{array}{l}\text { Dermal } \\
\text { Factor }\end{array}$ \\
\hline Hyaluronic Acid & $20 \mathrm{mg} / \mathrm{mL}$ & $20 \mathrm{mg} / \mathrm{mL}$ \\
\hline T3 & $0.09 \mu \mathrm{g} / \mathrm{mL}$ & \\
\hline T4 & $0.27 \mu \mathrm{g} / \mathrm{mL}$ & \\
\hline Insulin & $0.18 \mathrm{U} / \mathrm{mL}$ & \\
\hline Dimethyl amino ethanol & $0.09 \mathrm{gm} / \mathrm{mL}$ & $0.09 \mathrm{gm} / \mathrm{mL}$ \\
\hline Indomethacin & $0.71 \mathrm{mg} / \mathrm{mL}$ & \\
\hline Dexamethasone & $0.051 \mathrm{mg} / \mathrm{mL}$ & \\
\hline Fibroblast Growth Factor-2 & $10 \mathrm{ng} / \mathrm{mL}$ & \\
\hline Retinoic Acid & & $0.1 \mathrm{mg} / \mathrm{mL}$ \\
\hline Estriol & & $0.9 \mathrm{mg} / \mathrm{mL}$ \\
\hline
\end{tabular}


In order to recapitulate the clinical procedure we calculated the average number of MSCs in the fat aspirates, $2 \times 10^{6} / \mathrm{mL}$, and then calculated the volume of each factor to achieve $4 \times 10^{6}$ MSCs $/ \mathrm{mL}$. MSCs were cultured in adherent conditions with different amounts of factors. The concentrations of each factor mix spanned the level that recapitulated the amount used in the procedure in human subjects.

\section{Proliferation/Viability}

MSCs, treated or untreated, were assayed for cellular proliferation and viability using the CyQuant Cell Proliferation Assay Kit (Molecular Probes; Eugene, OR) and CellTiter-Blue Cell Viability Assay (Promega, Madison, WI), respectively as described (Greco et al (2011)).Proliferation was assessed in 96-well flat-bottomed plates. At the end of the experimental period, plates were placed at $-80^{\circ} \mathrm{C}$. The next day, the plates were thawed and then incubated in CyQuant GR dye/cell-lysis buffer for $5 \mathrm{~min}$ at room temperature. Fluorescence intensity was determined on a fluorescence microplate reader at $480 \mathrm{~nm}$ excitation/520 $\mathrm{nm}$ emission. Proliferation was calculated from a standard curve of known numbers of MSCs.

Viability was assessed with CellTiter-Blue reagent. Cultures were established as for the proliferation studies in 96-well plates. At the end of the assay period, CellTiter-Blue reagent was added to wells and the plates were incubated for $4 \mathrm{~h}$ at $37^{\circ} \mathrm{C}$. After this, wells were read using a fluorescence microplate reader at $560 \mathrm{~nm}$ excitation/590 $\mathrm{nm}$ emission. Percent viability was calculated from a reference of untreated MSCs, which were assigned $100 \%$ viability. Cell-free wells containing reagent alone were considered $0 \%$ viable.

\section{Adipogenic Differentiation of Adipose- Derived MSCs}

Adipogenic differentiation was performed with the Adipogenic hMSC Differentiation Bullet Kit (Cambrex Bio Science, Walkersville, MD) according to them anufacturer's recommendations and as previously described (Potian et al (2003)). Briefly, adipose-derived hMS Cwere seeded at a density of $4 \times 10^{4}$ cells/well in 6-well tissue culture plates. At confluence, adipogenic differentiation was performed with three cycles of induction/maintenance medium. Each cycle consisted of 3-day culture in adipogenic induction medium, followed by 13 days with adipogenic maintenance medium. This cycle was repeated for up to either 7 or 14 days, after which cells were washed with PBS, fixed with $10 \%$ formalin and stained with Oil Red 0, as described previously (13).

\section{Osteogenic Differentiation of Adipose- Derived MSCs}

Osteogenic differentiation was performed as previously described (13). Briefly, adiposederived hMSCwere seeded at a density of $4 \times 10^{4}$ cells/well in6-well tissue culture plates and allowed to adhere for $24 \mathrm{~h}$. Osteogeneic differentiation was induced in DMEM containing 10\% FCS, $100 \mathrm{nM}$ dexamethasone, $10 \mathrm{mM} \beta$-glycerophosphate and $50 \mu \mathrm{M} \mathrm{L}$ ascorbic acid-2-phosphate. Differentiation medium was replaced every 3-4 days for up to either 7 or 14 days, after which osteogenic differentiation was assessed by calcium deposition by Alzurin Red stain. Cells were fixed with $10 \%$ formalin, incubated in $60 \%$ isopropanol and then treated with Alzurin Red for 5 min and rinsed in PBS.

\section{Real Time RT-PCR}

RNA extraction was performed via RNeasy Mini Kit from (Qiagen, Valencia, CA). Total RNA $(1 \mu \mathrm{g})$ were immediately reverse transcribed using dNTPs $(0.2 \mathrm{mM})$, random hexamers $\left(\begin{array}{lll}50 & \mu \mathrm{M}\end{array}\right)$ and SuperScript III reverse transcriptase (200 U). Incubation conditions were $25^{\circ} \mathrm{C}$ for $5 \mathrm{~min}, 50^{\circ} \mathrm{C}$ for 60 min and $70^{\circ} \mathrm{C}$ for $15 \mathrm{~min}$. Real-time PCR was performed with 200 ngcDNA using Platinum SYBR Green qPCRSuperMix-UDG Kit (Invitrogen) and then analyzed on the 7300 Real-Time PCR System (Applied Biosystems, Foster City, CA). The analyses were performed with an initial incubation of $50^{\circ} \mathrm{C}$ for $2 \mathrm{~min}$ followed by $95^{\circ} \mathrm{C}$ for $2 \mathrm{~min}$. After this, the cycling conditions were as follows: $94^{\circ} \mathrm{C}$ for $15 \mathrm{sec}$ and $60^{\circ} \mathrm{C}$ for $45 \mathrm{sec}$, for 40 cycles. Primer sequences for $\mathrm{cEBP} \alpha$ are: Reverse, 5'-ACT GAT CGT GCT TCG TGT-3'; 
Forward, 5'-CCG AGT CAC ACC AGA AAG-3' and for PH-4,Reverse, 5'-GCT CGG ATG TTC TCA CTG-3' and Forward, 5'-GCG GGA CCT GAC TAG ATT-3'.

\section{Invasion Assay}

BD BioCoat ${ }^{\mathrm{TM}}$ Matrigel $^{\mathrm{TM}}$ Matrix $(0.2 \mathrm{ml})$ was added to $8 \mu \mathrm{m}$ Fluoro Blok cell culture inserts. These inserts prevent the plate reader from detecting emission in the upper chamber. After solidification of the Matrigel at $37^{\circ} \mathrm{C}$ for $1 \mathrm{~h}$, the inserts were placed in 24well culture plates containing $0.5 \mathrm{~mL}$ DMEM with $10 \%$ FCS. MSCs, $\left(2 \times 10^{4}\right)$, treated or untreated with different volumes of fat and/or dermal factors were diluted in serafree DMEM and then added to the inner wells. The cells were allowed to migrate for $2 \mathrm{~h}$ at $37^{\circ} \mathrm{C}$. After this, the inserts were removed, and the cells within the inner chambers were gently removed with a Q-tip. The wells under the membranes were then transferred to a second set of wells for labeling with $10 \mu \mathrm{M}$ CDFA-SE, diluted in PBS for $1 \mathrm{~h}$. After this, the wells were gently washed with PBS to remove excess CFDA-SE and then transferred to another well containing PBS for analyses on Victor 3V Multi-well plate reader (Perkin Elmer, Waltham, MA) at $485 \mathrm{~nm} / 535 \mathrm{~nm}$. Positive control included MDA-MB-231 breast cancer cells (American Type Culture Collection).

\section{Clonogenic Assays}

Clonogenic assays were performed as described (Rao et al (2004)). Briefly, MSCs $\left(10^{3} \mathrm{cell} / \mathrm{mL}\right)$, treated or untreated with fat and/or dermal factors were resuspended in $1.2 \%$ methylcellulose containing DMEM. Positive control cultures were performed with the breast cancer cell line, MDA-MB-231. One $\mathrm{mL}$ of cell suspension was added to 35mm suspension dishes, and the cultures were incubated for 1 week at $37^{\circ} \mathrm{C}$. Colonies with $>15$ cells were counted.

\section{Adipogenic Differentiation}

Control adipogenic differentiation was performed with the Differentiation Bullet Kit (Lonza, Walkersville, MD). The method followed the manufacturer's recommendations and as was described (Potian et al (2003) ). Briefly, MSC at $\sim 60$ $80 \%$ confluence were trypsinized and then replated at $5 \times 105$ cells/well in 6-well tissue culture plates. At cell confluence, adipogenic differentiation was performed with three cycles of induction/maintenance medium. Each cycle consisted of 3-day culture in adipogenic induction medium, followed by 13 days with adipogenic maintenance medium. Control wells were cultured, and medium was replaced on the same schedule using adipogenic maintenance medium. After the three-cycle schedule, cells were grown in adipogenic maintenance medium for 7 days, with change of medium every 3 days. After this, cells were washed with PBS, fixed with $10 \%$ formalin, stained with Oil Red 0 , and counterstained with hematoxylin.

\section{Statistical Analysis}

Statistical data analyses were performed with analysis of variance and Tukey-Kramer multiple comparisons test. $p<0.05$ was considered significant.

\section{Results}

\section{Components of Growth Factor}

We have developed a proprietary fat growth factor product that includes hyaluronic acid, insulin, dexamethasone, FGF, indomethacin, T3/T4 and dimethyl amino ethanol in a sterile water medium (Table 1). The components of this medium have all been associated with various effects on adipocytes and stem cells. Hyaluronic acid is used as a gel matrix scaffold to deliver the growth factor medium, and is known to bind CD44 that is expressed by MSCs. Its ability to bind to CD44 receptors on the stem cells was found to stabilize stem cells; and hyaluronic acid was used as a scaffold and delivery system of adipose derived stem cells in treating wounds as a dermal filler and in adipose tissue regeneration (Altman et al (2010), Chung et al (2010), Cervelli et al (2010) ). Hyaluronic acid itself is approved by the United States Food and Drug Administration as a dermal filler (Beer (2009)). 
Adipocytes express insulin receptors, and insulin is a critical hormone in glucose uptake and metabolism in fat cells in humans. Basically, both insulin and dexamethasone were shown to induce differentiation of MSCs to adipocytes in vitro (Nonomiya et al (2010)). Similarly, FGF can function to maintain proliferation and expansion of human adipose-derived stem cells in vitro, can maintain cell viability, and is important for their differentiation to adipocytes (Hebert et al (2009)). The prostagladin 2 inhibitor indomethacin also stimulates adipocyte derived stem cells to adipocytes and was shown to reduce immune response of adipocyte stem cells (Cui et al (2007). T3 and $\mathrm{T} 4$, endogenous thyroid hormones were shown to stimulate pre-adipocyte proliferation and differentiation (Ramsay et al (1989), Chen et al (1996)). Finally, dimethyl amino ethanol is a precursor of choline and is used by dermatologists and plastic surgeons to improve skin firmness and in clinical trials was reported to improve skin texture (Grossman (2005)).

\section{Pre-optimal Fat and/or Dermal Factors on MSC Proliferation and Viability}

We first studied the effects of fat and dermal factors at the lowest doses, $<0.01 \mathrm{~mL}$ treatment solution per volume of culture media. In all cases, there was no significant $(p<0.01)$ proliferation at $24 \mathrm{~h}$, except for dermal factor, which showed a slight increase in proliferation at the lowest dose (Figs 1A$1 \mathrm{C})$. The viability of MSCs at the same range showed a slight reduction at $0.01 \mathrm{~mL}$, but no change at other doses (Figures 1C-1F). In summary, the studies indicated non-toxic effects of fat and/or dermal factors at $<0.01$ $\mathrm{mL}$ volumes.

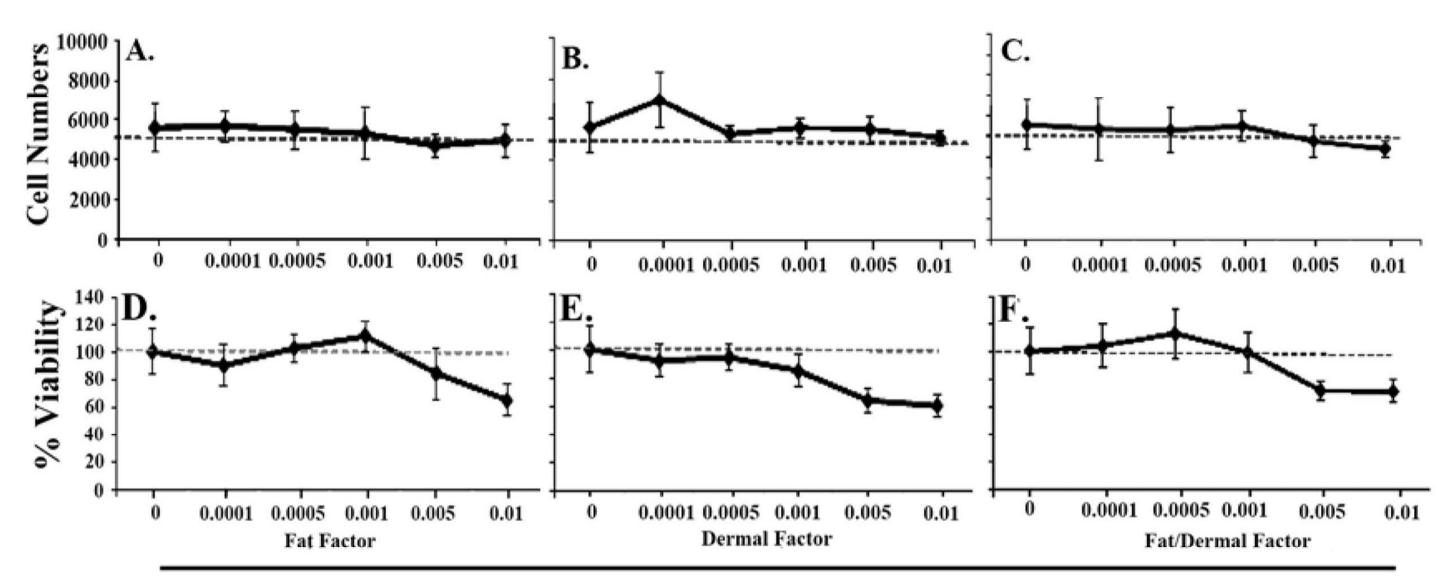

Volume $(\mathrm{mL}) / 4 \times 10^{6} \mathrm{MSCs}$

Fig.1. In Six Different Experiments, MSCs, Three from Bone Marrow and Three from Adipose Tissues, were Evaluated for Proliferation and Viability. MSCs $\left(4 \times 10^{4}\right)$ were Stimulated with Different Dosing Volumes of Fat (A and D), Dermal (B and E) or Combined Factors (C and F). Each Experiment was Performed with MSCs from a Different Donor. Proliferation (A-C) and Viability (D-F) were Assessed after $24 \mathrm{~h}$. The Dashed Lines Show the Baseline/Seeded MSCs. The Results are Presented as the Mean Number of Cells \pm SD.

\section{Proliferative Effects of Post-Optimal Fat and/or Dermal Factors}

Next, we repeated the studies at higher doses. As expected, untreated MSCs proliferated, without the addition of factors. At $0.01 \mathrm{~mL}$, cell proliferation was noted only in cultures with dermal factor (Fig. 2B). This proliferation was reduced at the higher concentrations after 24 and $48 \mathrm{~h}$. The purpose was to evaluate if the decreased or blunted proliferation could be explained by reduced viability. We next tested the viability of fat and/or dermal factors on MSCs at the same concentrations as for the proliferation studies. At the $0.01 \mathrm{~mL}$ dose, the viability was similar $(p>0.01)$ to untreated MSCs. However, the volumes of factors were proportional to 
cell death (Figs 2C-2F). Together, the results indicate that at higher concentrations, fat and/or dermal factors caused minimal proliferation that appears to be partly explained by cell death.
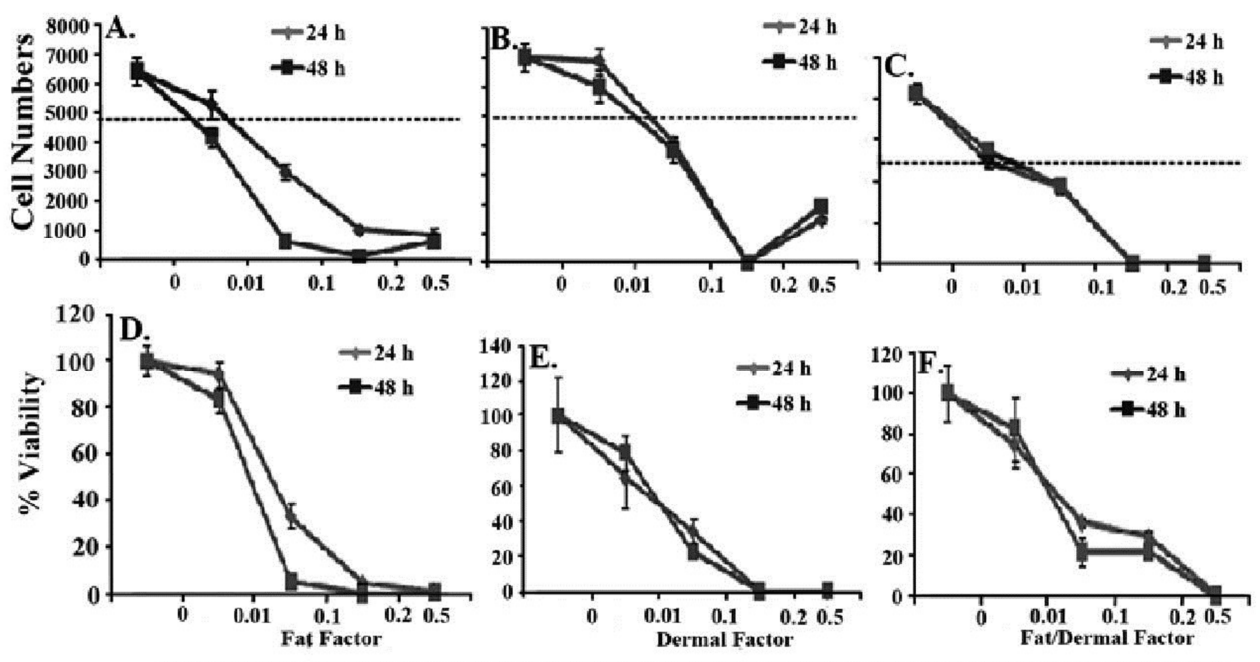

Volume $(\mathrm{mL}) / 4 \times 10^{6} \mathrm{MSCs}$

Fig.2. In Six Different Experiments, Three with MSCs from Bone Marrow and Three from Adipose Tissues were Evaluated for Proliferation. MSCs $\left(4 \times 10^{4}\right)$ were Stimulated with Different Dosing Volumes of Fat (A and D), Dermal (B and E) or Combined Factors (C and F). Each Experiment was Performed with MSCs from a Different Donor. Proliferation (A-C) and Viability (D-F) were Assessed after 24 and $48 \mathrm{~h}$. The Dashed Lines Show the Baseline/Seeded MSCs. The Results are Presented as the Mean Number of Cells \pm SD.

\section{Fat/Dermal Differentiation of MSCs}

Factor-Induced

We next investigated if reduced proliferation (Fig. 1) could be explained by rapid differentiation of the fat/dermal-treated MSCs. MSCs, $10^{4} / \mathrm{mL}$, were treated with $<0.05$ $\mathrm{mL}$ dose of fat and/or dermal factors as well as $\log _{10}$ fold less volumes. After $24 \mathrm{~h}$, the cultures were examined morphologically with an inverted microscope. Representative images at 100x magnification indicated $>95 \%$ of the fat factor seeded cells were associated with fat globules, indicating differentiation towards adipogenic cells (Fig. 3A).

In order to discriminate between adipogenic and osteogenic differentiation with MSCs from bone marrow and adipose tissues, and to determine whether the induction was rapid, we treated MSCs with non-toxic concentrations of fat and/or dermal factors for $24 \mathrm{~h}$ and then determined whether the
MSCs showed rapid differentiation. We analyzed the cells after 7 and 14 days of factor withdrawal for adipogenic and osteogenic differentiation. There was no evidence of osteogenic formation (Fig.3B), indicating lineage differentiation. After treatment, the differentiation was monopotent towards adipogenesis. The size of the adipogenic cultures showed a timeline increase with large clusters at day 7 (Fig. 3B). Control MSCs were treated with differentiating agents from a commercial source (Fig. 3C). At day 14, although there were some adipogenic cells, most of the nonadipogenic cells survived. Since there was no evidence of necrotic cells, the results indicated that the 24-h treatment was sufficient to induce the differentiation of MSCs. However, the differentiation during this 24-h period appears to be at an early stage of lineage differentiation. The fat factor had to be present throughout the culture to achieve adipogenesis. 
Fig. 3B indicates that fat and/or dermal factors can induce MSCs to differentiate toward adipose lineage. We therefore performed real-time PCR for $\mathrm{cEBP} \alpha$ (CCAAT/enhancer-binding protein alpha) as a surrogate marker of adipogenesis (Rosen (2005)). The cells were treated for $24 \mathrm{~h}$ with different amounts of non-toxic doses of fat and/or dermal factors.
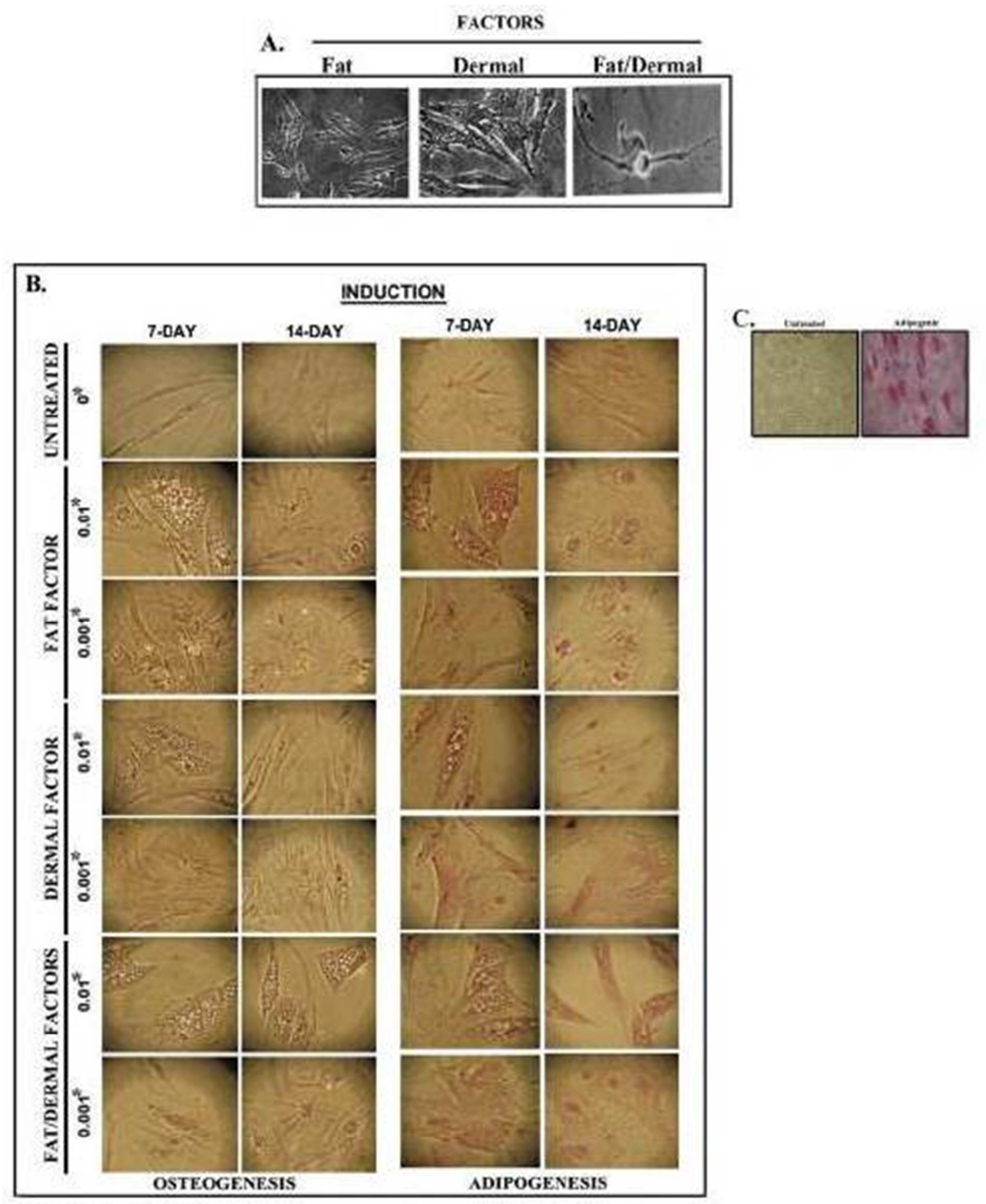

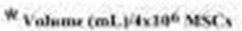

Fig. 3. Effects of Fat and/Ordermal Treatments on MSC-Inducedadipo- and Osteogenic Differentiation. MSCs from BM or Adipose Tissues were Treated for $24 \mathrm{~h}$ with Fat and/or Dermal Treatments or Untreated. A) Shown are the Morphologies of Treated Cells. B) At 7and 14-Day Exposures, Cells were Labeled for Adipo- and Osteogenic Differentiation. Shown are Representative Inductions. C) Control Adipogenesis is Shown with MSCs with Commercial Differentiating Agents. 
The values for untreated MSCs were normalized to 1 and the results of treated cells were presented as fold changes over untreated MSCs (Fig. 4A). There were significant $(p<0.05)$ differences at $0.1 \mathrm{~mL}$, and only with dermal and fat/dermal treatment, indicating that at the early time point, the cells begin to differentiate, but the early adipogenic cells were progenitors and not late stage fat cells. This was confirmed by the lack of 24-h treated MSCs to be labeled with Oil Red $O$ (not shown).
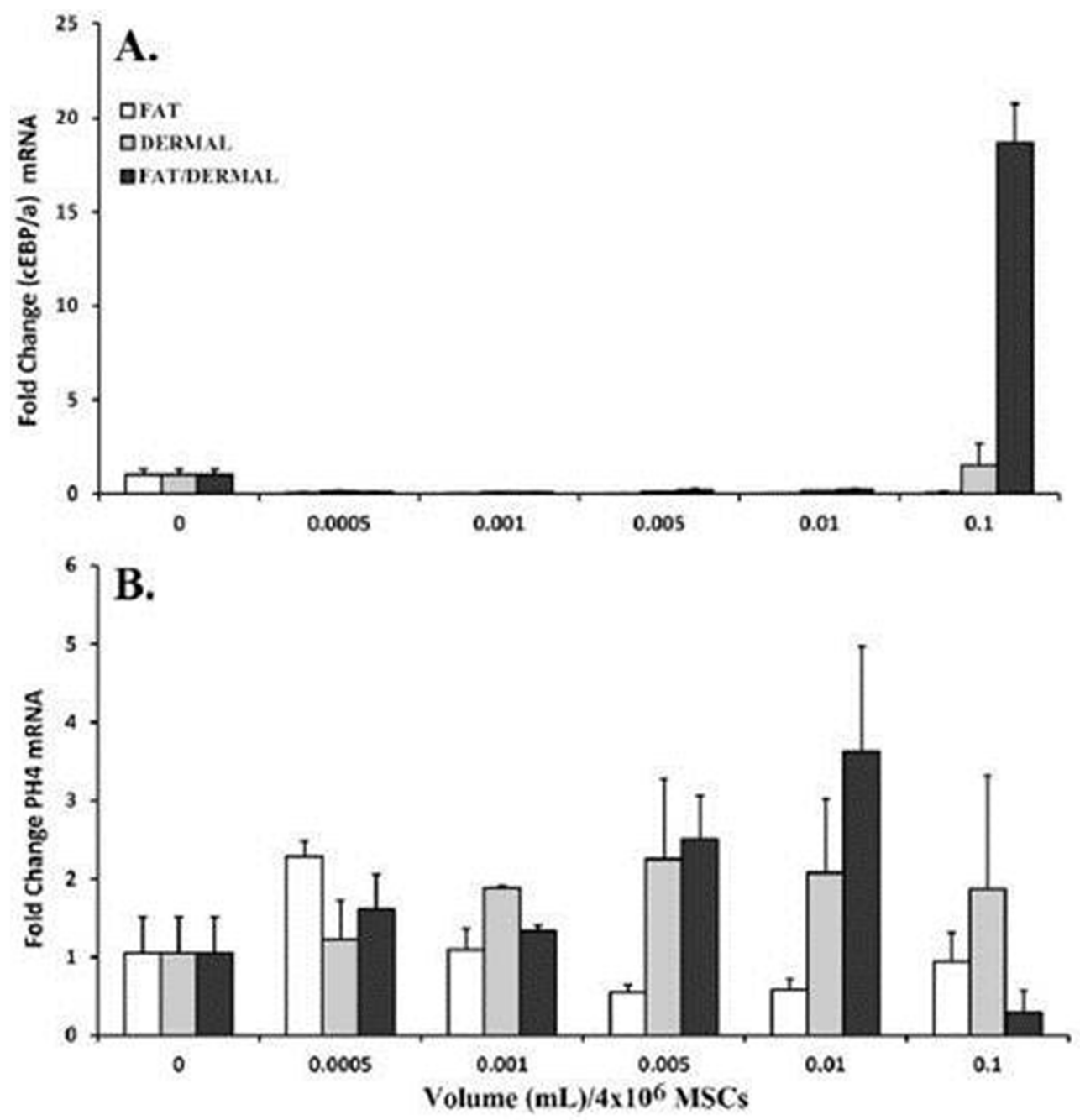

Fig. 4. MSCs (4x104) from Bone Marrow Aspirates and Adipose Tissues were Treated for $24 \mathrm{~h}$ with Different Dosing Volumes. Following the Treatment Period, RNA was Extracted and Immediately Reverse Transcribed. Real-time PCR was Performed with 200 ngcDNA and then Analyzed for Expression of the Surrogate Adipose and Fibroblast Markers, (A) CEBP $\alpha$ and (B) PH4, Respectively. The Results are Presented as the Mean \pm SD Fold Change Over Untreated MSCs, which were Designated a Value of One; $n=6$.

We repeated the real-time RT-PCR, except that it was with primers for the surrogate fibroblast marker (proly-4-hydroxlase, PH4). The values for untreated MSCs were normalized to 1 and the experimental points were presented as fold change over untreated
MSCs. At $>0.005 \mathrm{~mL}$ there was significant $(p<0.05)$ increase in PH4 by dermal and fat/dermal factors. The values were reduced at 0.1 . This however was expected since this concentration was shown to be toxic (Fig. 2). 


\section{Safety of Fat/Dermal-Treated MSCs}

We were concerned that treatment with fat and/or dermal factors could result in fibrosis. We therefore treated MSCs from bone marrow and adipose tissues with different concentrations of fat and/or dermal factors and then examined the cultures daily up to four weeks for cell proliferation as an indicator of fibrosis. After four weeks there was no evidence of fibroblast differentiation based on cell morphology and surmised that extended periods of treatment did not induce fibrosis (Fig. 5).

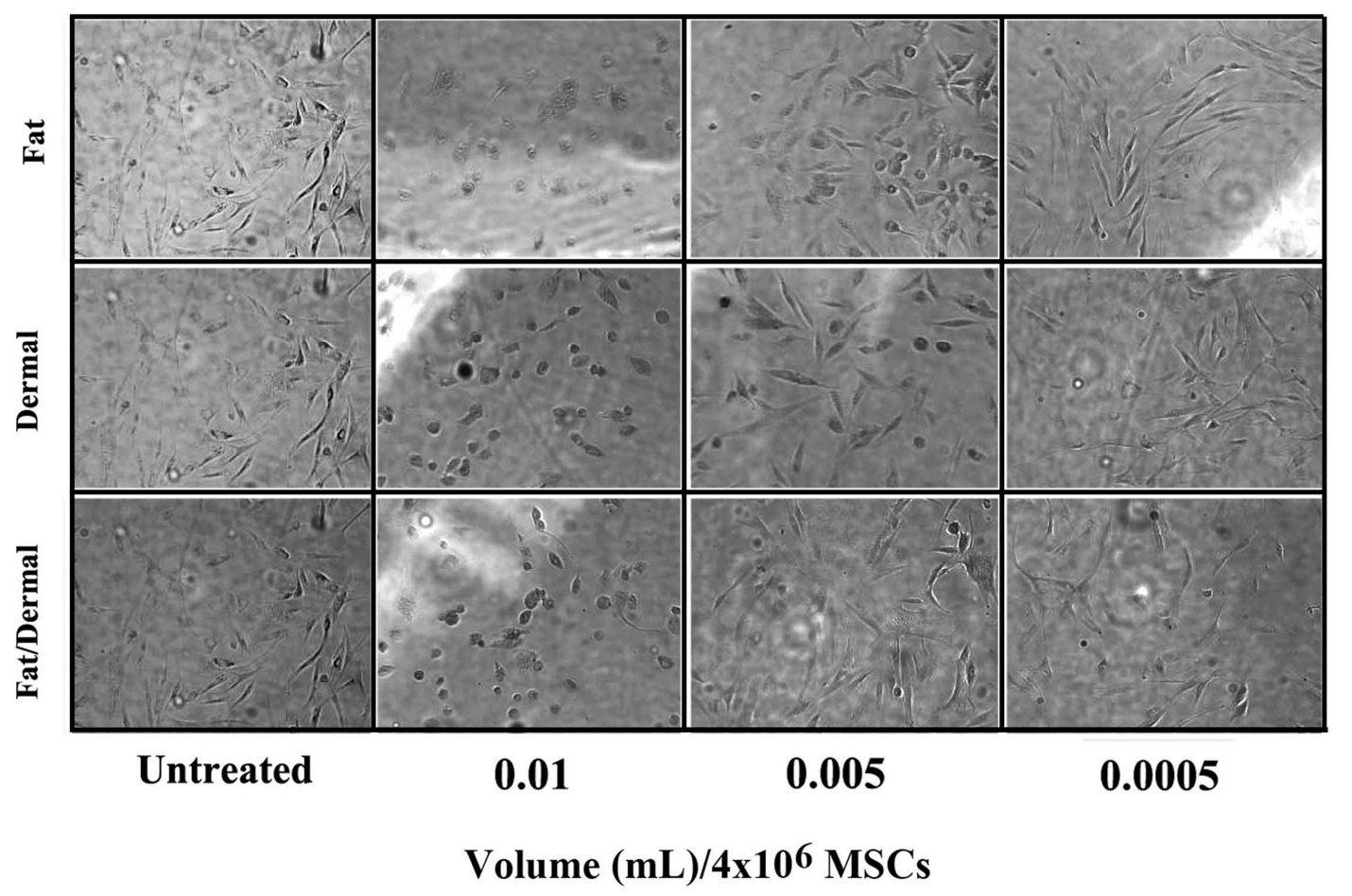

Fig. 5. MSCs from Bone Marrow or Liposuction Aspirates were Treated with Different Concentrations of Fat and/or Dermal Factors. After $24 \mathrm{~h}$, the Factors were Removed and the Cultures were Re-Incubated for Four Weeks. Shown are Representative Images (40 x) of Each Experimental Point.

We repeated the studies and examined the ability of treated MSCs to grow in a contactindependent manner in methylcellulose matrix, and also to invade matrices towards sera. Positive controls were performed with breast cancer cells. As compared to the breast cancer cells and untreated MSCs, the 24-h treated cells showed significantly $(p<0.01)$ fewer colonies, indicating lack of transformation (Fig. 6A). This was further supported by the significantly $(p<0.01)$ reduced invasion towards sera (Fig.6B). The cells could not be passaged, indicating differentiation (not shown). In summary, there is no evidence of transformation of MSCs after four weeks of treatment with fat and/or dermal factors. 

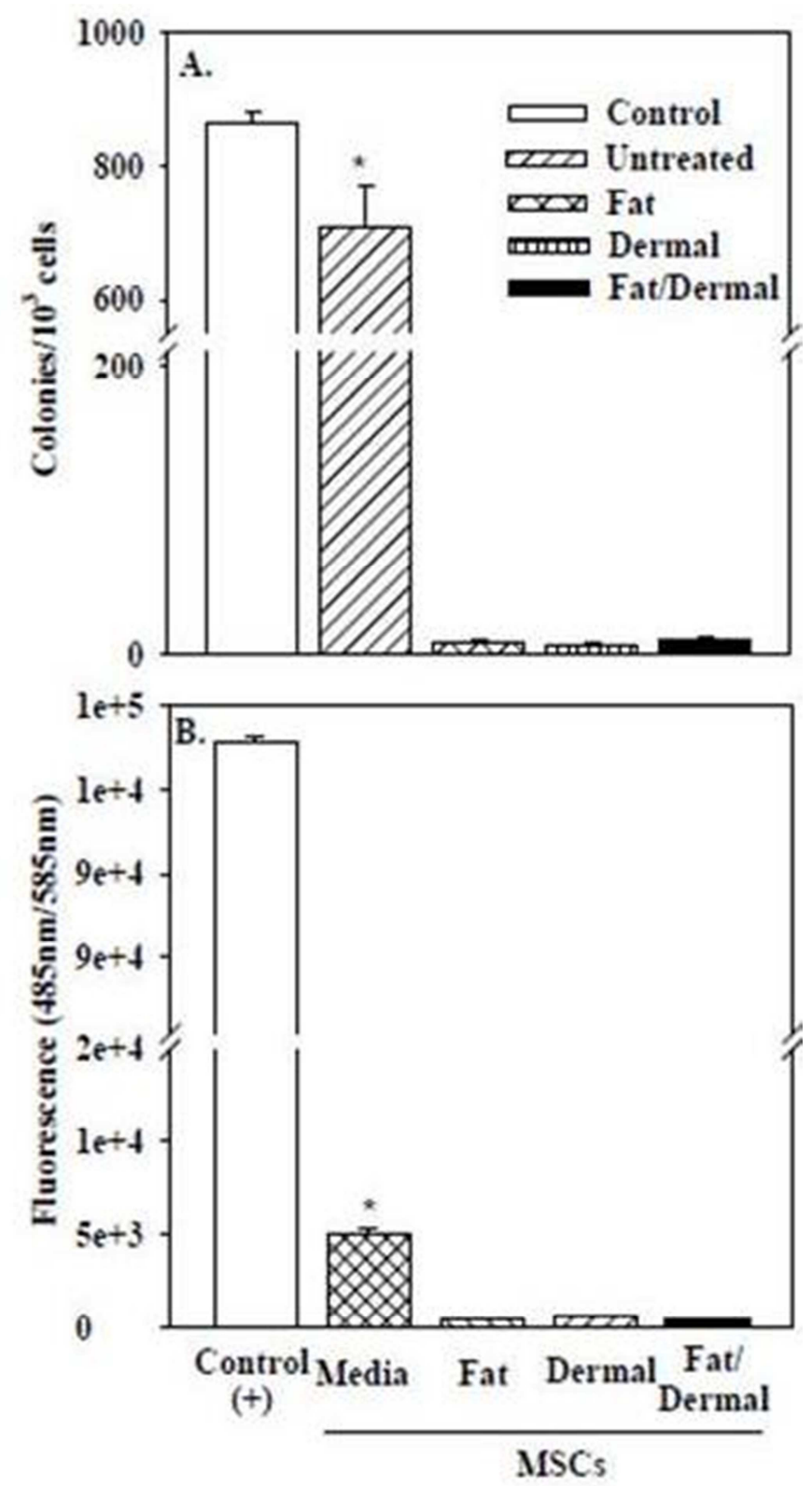

Fig. 6. (A) Clonogenic Assays were Performed for Colonies with MSCs, Untreated or Treated with Different Volumes of Fat and/or Dermal Factors. After $24 \mathrm{~h}$, the Factors were Removed and the Cells were Studied for Colonies in Methycellulose Matrix. (B) For the Cell Invasion Assay, MSCs or Positive Control MDA-MB-231 Breast Cancer Cells (American Type Culture Collection) were Treated or Untreated with Various Doses of Fat and/or Dermal Factors and Allowed to Migrate for $\mathbf{2} \mathrm{h}$. Cells were Labeled with CDFA-SE and Transferred to Another Well Containing PBS for Fluorimetric Analyses. The Results were Similar for all Treatment Doses and Representative Data from $0.01 \mathrm{~mL}$ Dose is Shown. The Results are Presented as the Mean \pm SD of Six Experiments, Each with MSCs from a Different Donor.

${ }^{*} p<0.01$ vs. treated MSCs

Denis O. Rodgerson, Alan Harris, Vincent C Giampapa, Steven J. Greco, David O'Neill and Pranela Rameshwar (2013), Advances in Stem Cells, DOI: 10.5171/2013.716906 


\section{Discussion}

The experiments presented here examine the toxicity and potential mechanism of action of two formulations of growth differentiation factors for use in skin and soft tissue regeneration. Experiments examining a doseresponse effect of the factor formulations, either alone and in combination, on cell proliferation and viability of MSCs showed no evidence of toxicity at low concentrations. The lack of cell proliferation at low concentrations appeared to be due to rapid MSC differentiation into adipose cells induced by the factors, as determined by function, phenotype and gene expression studies. At higher factor doses, cell death was observed. There was no evidence of fibroblast differentiation, osteogenesis or oncogenic transformation of MSCs when exposed to either factor mixture or to the two mixtures combined.. .

The findings are promising for tissue regeneration in cases involving wounds, burns and loss of facial volume, either traumatic- or age- related, where these factors would have a therapeutic benefit through adipose filling. It is expected that the combination of these factors with off-theshelf MSCs will have utility for immediate allogeneic application in an acute injury as in war-related wounds, in cases where the subject cannot ethically donate bone marrow, or if there is unavailable excess fat. It will also be interesting to test other types of stem cells for these procedures. The formulations studied show a rapid method to induce adipogenesis as compared to weeks of differentiation required by the established method as shown in Fig. 3C. In conclusion, the two factor formulations described here show similar responses, regardless whether MSCs were obtained from bone marrow or adipose tissues. The relevant levels were not toxic and induced differentiation within $24 \mathrm{~h}$. These observations, combined with undetectable functional osteogenesis, support the safety of the factors. These are necessary studies before proceeding to further multicenter clinical trials in patients for tissue regeneration.

\section{Author Disclosure Statement:}

PR and SJG have no conflict of interest to declare.

$\mathrm{AH}$ was an employee and stockholder in NeoStem, Inc. at the time of contribution but is no longer affiliated with NeoStem, Inc.

DR is an employee and holds stock in NeoStem, Inc.

DO is an employee of NeoStem, Inc.

VG is on anadvisory board of NeoStem; holds stock in NeoStem and holds the patent rights of the formulations.

\section{References}

Altman, A. M., Abdul Khalek, F. J., Seidensticker, M., Pinilla, S., Yan, Y., Coleman, M., Song, Y.- H., Butler, C. E. \& Alt, E. U. (2010). "Human Tissue-Resident Stem Cells Combined with Hyaluronic Acid Gel Provide Fibrovascular-Integrated Soft-Tissue Augmentation in a Murine Photoaged Skin Model," Plast.Reconstr. Surg, 125:63-73.

Beer, K. (2009). "Dermal Fillers and Combinations of Fillers for Facial Rejuvenation," Dermatologic Clinics, 27:427432.

Buron, F., Perrin, H., Malcus, C. Héquet, O., Thaunat, O., Kholopp-Sarda, M.- N., Moulin, F. T. \& Morelon, E. (2009). "Human Mesenchymal Stem Cells and Immunosuppressive Drug Interactions in Allogeneic Responses: An In Vitro Study Using Human Cells," Transplant. Proc., 41:3347-3352.

Campagnoli, C., Roberts, I. A. G., Kumar, S., Bennett, P. R., Bellantuono, I. \& Fisk, N. M. (2001). "Identification of Mesenchymal Stem/Progenitor Cells in Human FirstTrimester Fetal Blood, Liver, and Bone Marrow," Blood, 98:2396-2402.

Castillo, M., Liu, K., Bonilla, L. \& Rameshwar, P. (2007). "The Immune Properties of Mesenchymal Stem Cells," Intl J Biomed Sci, 3:100:100-104. 
Cervelli, V., De, A. B., Lucarini, L., et al. (2010). "Tissue Regeneration in Loss of Substance on the Lower Limbs through Use of Platelet-Rich Plasma, Stem Cells from Adipose Tissue, and Hyaluronic Acid," Adv. Skin WoundCare, 23:262-272.

Chan, J. L., Tang, K. C., Patel, A. P., Bonilla, L. M., Pierobon, N., Ponzio, N. M. \& Rameshwar, P. (2006). "Antigen-Presenting Property of Mesenchymal Stem Cells Occurs during a Narrow Window at Low Levels of InterferonGamma," Blood, 107:4817-4824.

Chen, N. X., Hausman, G. J., Minish, R. C. \& Wright, J. T. (1996). "Influence of Thyroxine in Vivo on Preadipocyte Development and Insulin-Like Growth Factor-I and IGF Binding Protein Secretion in Fetal Stromal Vascular Cell Cultures," Obes.Res, 4:357-366.

Cho, J., Rameshwar, P. \& Sadoshima, J. (2009). "Distinct Roles of Glycogen Synthase Kinase (GSK)-3beta and GSK-3beta in Mediating Cardiomyocyte Differentiation in Murine Bone Marrow-derived Mesenchymal Stem Cells," Journal of Biological Chemistry, 284:36647-36658.

Cho, K. J., Trzaska, K. A., Greco, S. J., et al. (2005). "Neurons Derived from Human Mesenchymal Stem Cells Show Synaptic Transmission and Can be Induced to Produce the Neurotransmitter Substance $P$ by Interleukin-1 Alpha," Stem Cells, 23:383-391.

Chung, H. J., Jung, J. S. \& Park, T. G. (2010). "Fabrication of Adipose-Derived Mesenchymal Stem Cell Aggregates Using Biodegradable Porous Microspheres for Injectable Adipose Tissue Regeneration," J Biomaterial Science PolymEd,

Cui, L., Yin, S., Liu, W. Li, N., Zhang, W. \& Cao, Y. (2007). "Expanded Adipose-Derived Stem Cells Suppress Mixed Lymphocyte Reaction by Secretion of Prostaglandin E2," Tissue Eng, 13:1185-1195.

Dominici, M., Paolucci, P. \& Conte, P., Horwitz, E. M. (2009). "Heterogeneity of Multipotent Mesenchymal Stromal Cells: from Stromal Cells to Stem Cells and Vice Versa," Transplantation, 87:S36-S42.
Greco, S., Patel, S. A., Bryan, M., et al. (2011). "AMD3100-Mediated Production of Interleukin-1 from Mesenchymal Stem Cells is Key to Chemosensitivity of Breast Cancer Cells," Am J Cancer Res, 1:701-715.

Greco, S. J. \& Rameshwar, P. (2007). 'Enhancing Effect of IL-1 \{alpha\} on Neurogenesis from Adult Human Mesenchymal Stem Cells: Implication for Inflammatory Mediators in Regenerative Medicine,' J Immunol, 179:3342-3350.

Greco, S. J. \& Rameshwar, P. (2008). "Microenvironmental Considerations in the Application of Human Mesenchymal Stem Cells in Regenerative Therapies," Biologics., 2:699-705.

Greco, S. J., Smirnov, S. V., Murthy, R. C. \& Rameshwar, P. (2007). "Synergy between RE1 Silencer of Transcription (REST) and NFkappaB in the Repression of the Neurotransmitter Gene Tac1 in Human Mesenchymal Stem Cells: Implication for Microenvironmental Influence on Stem Cell Therapies," J Biol Chem, 282:30039-30050.

Greco, S. J., Zhou, C., Ye, J. H. \& Rameshwar, P. (2007). "An Interdisciplinary Approach and Characterization of Neuronal Cells Transdifferentiated from Human Mesenchymal Stem Cells," Stem Cells Dev, 16:811-826.

Grossman, R. (2005). "The Role of Dimethylaminoethanol in Cosmetic Dermatology," Am J Clin Dermatol., 6:39-47.

Hebert, T. L., Wu, X., Yu, G., et al. (2009). "Culture Effects of Epidermal Growth Factor (EGF) and Basic Fibroblast Growth Factor (bFGF) on Cryopreserved Human AdiposeDerived Stromal/Stem Cell Proliferation and Adipogenesis," J Tissue Eng Regen Med, 3:553561.

Isakova, I. A., Baker, K., DuTreil, M., Dufour, J., Gaupp, D. \& Phinney, D. G. (2007). "Age- and Dose-Related Effects on MSC Engraftment Levels and Anatomical Distribution in the Central Nervous Systems of Nonhuman Primates: Identification of Novel MSC 
Subpopulations That Respond to Guidance Cues in Brain," Stem Cells, 25:3261-3270.

Kim, N. R., Kang, S. K., Ahn, H. H., et al. (2009). "Discovery of a New and Efficient Small Molecule for Neuronal Differentiation from Mesenchymal Stem Cell," Journal of Medicinal Chemistry, 52:7931-7933.

Kreisler, A., Strissel, P. L., Strick, R., et al. (2010). "Regulation of the NRSF/REST Gene by Methylation and CREB Affects the Cellular Phenotype of Small-Cell Lung Cancer," Oncogene, 29:5828-5838.

Le Blanc, K., Frassoni, F., Ball, L., et al. (2008). "Mesenchymal Stem Cells for Treatment of Steroid-Resistant, Severe, Acute Graft-versusHost Disease: A Phase II Study," The Lancet, 371:1579-1586.

Majumader, S. (2006). "REST In Good Times and Bad: Roles in Tumor Suppressor and Oncogenic Activities," Cell Cycle, 5:19291935.

Mohseny, A. B., Szuhai, K., Romeo, S., et al. (2009). "Osteosarcoma Originates from Mesenchymal Stem Cells in Consequence of an Euploidization and Genomic Loss of Cdkn2," J Pathol, 219:294-305.

Molcanyi, M., Riess, P., Haj-Yasein, N. N., et al. (2009). "Developmental Potential of the Murine Embryonic Stem Cells Transplanted into the Healthy Rat Brain--Novel Insights into Tumorigenesis," Cell Physiol Biochem., 24:87-94.

Momin, E. N., Mohyeldin, A., Zaidi, H. A., et al. (2010). "Mesenchymal Stem Cells: New Approaches for the Treatment of Neurological Diseases," Curr Stem Cell Res Ther, 5:326-344.

Ninomiya, Y., Sugahara-Yamashita, Y., Nakachi, Y., et al. (2010). "Development of a Rapid Culture Method to Induce Adipocyte Differentiation of Human Bone MarrowDerived Mesenchymal Stem Cells," Biochemical and Biophys Res Commun, 394:303-308.

Patel, N., Klassert, T. E., Greco, S. J., et al. (2012). "Developmental Regulation of TAC1 in Peptidergic-Induced Human Mesenchymal Stem Cells: Implication for Spinal Cord Injury in Zebra Fish," Stem Cells Dev., 21:308-320.

Potian, J. A., Aviv, H., Ponzio, N. M., Harrison, J. S. \& Rameshwar, P. (2003). "Veto-Like Activity of Mesenchymal Stem Cells: Functional Discrimination between Cellular Responses to Alloantigens and Recall Antigens," J Immunol, 171:3426-3434.

Ra, J. C., Shin, I. S. \& Kim, S. H. (2011). "Safety of Intravenous Infusion of Human Adipose Tissue-Derived Mesenchymal Stem Cells in Animals and Humans," Stem Cells and Development, 20:1297-1308.

Ramsay, T. G., Wolverton, C. K., Hausman, G. J., et al. (1989). "Alterations in Adipogenic and Mitogenic Activity of Porcine Serum in Response to Hypophysectomy," Endocrinology, 124:2268-2276.

Rao, G., Patel, P. S., Idler, S. P., Maloof, P., Gascon, P., Potian, J. A. \& Rameshwar, P. (2004). "Facilitating Role of Preprotachykinin-I Gene in the Integration of Breast Cancer Cells within the Stromal Compartment of the Bone Marrow: A Model of Early Cancer Progression," Cancer Res, 64:2874-2881.

Romieu-Mourez, R., Francois, M., Boivin, M. N., et al. (2007). "Regulation of MHC Class II Expression and Antigen Processing in Murine and Human Mesenchymal Stromal Cells by IFN- \{gamma\}, TGF-beta, and Cell Density," J Immunol, 179:1549-1558.

Rosen, E. D. (2005). "The Transcriptional Basis of Adipocyte Development," Prostaglandins, Leukotrienes and Essential Fatty Acids, 73:31-34.

Rosland, G. V., Svendsen, A., Torsvik, A., et al. (2009). Derived Human Mesenchymal Stem Cells- "Long-term Cultures of Bone Marrow Frequently Undergo Spontaneous Malignant Transformation," Cancer Research, 69:53315339.

Sakaguchi, Y., Sekiya, I., Yagishita, K., Ichinose, S., Shinomiya, K. \& Muneta, T. (2004). "Suspended Cells from Trabecular Bone by Collagenase Digestion Become Virtually 
Identical to Mesenchymal Stem Cells Obtained from Marrow Aspirates," Blood, 104:2728-2735.

Sherman, L. S., Munoz, J., Patel, S. A., et al. (2011). "Moving from the Laboratory Bench to Patients-Bedside: Considerations for Effective Therapy with Stem Cells," Clinical and Translational Science, 4:380-386.

Stagg, J. (2007). "Immune Regulation by Mesenchymal Stem Cells: Two Sides to the Coin," Tissue Antigens, 69:1-9.

Tang, K. C., Trzaska, K. A., Smirnov, S. V., Kotenko, S. V., Schwander, S. K., Ellner, J. J. \& Rameshwar, P. (2008). "Down-Regulation of MHC II in Mesenchymal Stem Cells at High IFN-\{gamma\} Can Be Partly Explained by Cytoplasmic Retention of CIITA," J Immunol, 180:1826-1833.

Tao, X. R., Li, W. L., Su, J., et al. (2009). "Clonal Mesenchymal Stem Cells Derived from Human Bone Marrow can Differentiate into Hepatocyte-Like Cells in Injured Livers of SCID Mice," J Cell Biochem., 108:693-704.

Totey, S., Totey, S. \& Pal, R. (2009). "Adult Stem Cells: A Clinical Update," J Stem Cells, 4: 105-121.

Trzaska, K. A., King, C. C., Li, K. Y., et al. (2009). "Brain-Derived Neurotrophic Factor Facilitates Maturation of Mesenchymal Stem Cell-Derived Dopamine Progenitors to Functional Neurons," Journal of Neurochemistry, 110:1058-1069.

Wang, Y., Zhang, A., Ye, Z., Xie, H. \& Zheng, S. (2009). "Bone Marrow-Derived Mesenchymal Stem Cells Inhibit Acute Rejection of Rat Liver Allografts in Association with Regulatory TCell Expansion," Transplant. Proc., 41:43524356.

Yan, Y., Yang, D., Zarnowska, E. D., et al. (2005). "Directed Differentiation of Dopaminergic Neuronal Subtypes from Human Embryonic Stem Cells," Stem Cells, 23:781-790.

Yoshimura, K., Shigeura, T. \& Matsumoto, D., Sato, T., Takaki, Y., Aiba-Kojima, E., Sato, K.,
Inoue, K., Nagase, T. \& Koshima, I. (2006). "Characterization of Freshly Isolated and Cultured Cells Derived from the Fatty and Fluid Portions of Liposuction Aspirates," J Cell Physio., 208:64-76. 